\title{
UNIFORM EXPONENTIAL STABILITY IN THE SENSE OF HYERS AND ULAM FOR PERIODIC TIME VARYING LINEAR SYSTEMS
}

\section{BAKHT ZADA}

Abstract. We prove that the uniform exponential stability of time depended $p$-periodic system

$$
\dot{\Psi}(t)=\Pi(t) \Psi(t), \quad t \in \mathbb{R}_{+}, \Psi(t) \in \mathbb{C}^{n}
$$

is equivalent to its Hyers-Ulam stability. As a tool, we consider the exact solution of the Cauchy problem

$$
\left\{\begin{array}{l}
\dot{\Theta}(t)=\Pi(t) \Theta(t)+e^{i \alpha t} \zeta(t), \quad t \in \mathbb{R}_{+} \\
\Theta(0)=\Theta_{0}
\end{array}\right.
$$

as the approximate solution of $\dot{\Psi}(t)=\Pi(t) \Psi(t), t \in \mathbb{R}_{+}, \Psi(t) \in \mathbb{C}^{n}$, where $\alpha$ is any real number, $\zeta(t)$ with $\zeta(0)=0$, is a $p$-periodic bounded function on the Banach space $\mathscr{S}\left(\mathbb{R}_{+}, \mathbb{C}^{n}\right)$. More precisely we prove that the system $\dot{\Psi}(t)=\Pi(t) \Psi(t), t \in \mathbb{R}_{+}, \Psi(t) \in \mathbb{C}^{n}$ is Hyers-Ulam stable if and only if it is exponentially stable. We argue that Hyers-Ulam stability concept is quite significant in realistic problems in numerical analysis and economics.

Mathematics subject classification (2010): 34K20, 34C25, 34K13.

Keywords and phrases: Uniform exponential stability, Hyers-Ulam stability, linear periodic system.

\section{REFERENCES}

[1] C. Alsina AND R. GER, On some inequalities and stability results related to the exponential function, J. Inequal. Appl. 2, 4(1998), 373-380.

[2] S. ANDRÁS AND A. R. MÉsZÁRos, Ulam-Hyers stability of dynamic equations on time scales via Picard operators, Appl. Math. Comput. 219, (2013), 4853-4864.

[3] S. ARShAD, C. BuŞE AND O. SAIERLI, Connections between exponential stability and boundedness of solutions of a couple of differential time dependending and periodic systems, Electron. J. Qual. Theory Differ. Equ. 90, (2011), 1-16.

[4] S. Arshad, C. Buşe, A. Nosheen And A. ZAda, Connections between stability of poincare map and boundedness of certain associate sequence, Electron. J. Qual. Theory Differ. Equ. 16, (2011), $1-12$.

[5] C. J. K. BATTY AND R. Chill, Bounded convolutions and solutions of inhomogeneous Cauchy problems, Forum. Math. 11, 2 (1999), 253-277.

[6] C. BuşE AND A. ZADA, Boundedness and exponential stability for periodic time dependent systems, Electron. J. Qual. Theory Differ. Equ. 37, (2009), 1-9 .

[7] C. ChICONE AND Y. LATUSHKIN, Evolution semigroups in dynamical systems and differential equations, Amer. Math. Soc., 1999.

[8] J. Chung, Hyers-Ulam-Rassias stability of Cauchy equation in the space of Schwartz distributions, J. Math. Anal. Appl. 300, (2004), 343-350.

[9] R. DATKO, Uniform asymptotic stability of evolutionary processes in a Banach space, SIAM J. Math. Anal. 3, (1972), 428-445.

[10] G.-L. FORTI, Elementary remarks on Ulam-Hyers stability of linear functional equations, J. Math. Anal. Appl. 328, (2007), 109-118.

[11] J. Huang And Y. Li, Hyers-Ulam stability of linear functional differential equations, J. Math. Anal. Appl. 426, (2015), 1192-1200. 
[12] D. H. HyERS, On the stability of the linear functional equation, Proc. Nat. Acad. Sci. U.S.A., 27, (1941), 222-224.

[13] S.-M. Jung, Hyers-Ulam stability of linear differential equations of first order. III, J. Math. Anal. Appl. 311, (2005), 139-146.

[14] S.-M. JUNG, Hyers-Ulam stability of a system of first order linear differential equations with constant coefficients, J. Math. Anal. Appl. 320, (2006), 549-561.

[15] S. NAITO AND N. VAN MINH, Evolution semigroups and spectral criteria for almost periodic solutions of periodic evolution equations, J. Diff. Equations 152, (1999), 338-376.

[16] N. VAN Minh, F. RABIGER AND R. SCHNAUBELT, Exponential stability, exponential expansiveness, and exponential dichotomy of evolution equations on the half-line, Integral Equations Operator Theory 32, (1998), 332-353.

[17] M. OвŁOZA, Hyers stability of the linear differential equation, Rocznik Nauk.-Dydakt. Prace Mat. 13, (1993), 259-270.

[18] S. E. Takahasi, H. Takagi, T. Miura and S. Miyajima, On the Hyers-Ulam stability of the Banach space-valued differential equation $y^{\prime}=\lambda y$, Bull. Korean Math. Soc. 39, (2002), 309-315.

[19] S. M. ULAM, A collection of the mathematical problems, Interscience Publisheres, New York-London, 1960.

[20] S. M. Ulam, Problem in modern mathematics, Science Editions, J. Wiley and Sons, Inc., New York, 1964.

[21] A. ZADA, O. SHAH AND R. SHAH, Hyers-Ulam stability of non-autonomous systems in terms of boundedness of Cauchy problems, Appl. Math. and Comp. 271, (2015), 512-518.

[22] A. ZADA, N. Ahmad AND I. U. KHAN, On the exponential stability of discrete semigroups, Qual. Theory Dyn. Sys., 2014. 